\title{
Q fever seroprevalence in parturient women: the EQRUN cross-sectional study on Reunion Island
}

Julien Jaubert ${ }^{1}$, Laura Atiana ${ }^{1}$, Sophie Larrieu ${ }^{2}$, Philippe De Vos ${ }^{3}$, Claudine Somon-Payet ${ }^{4}$, Sylvaine Porcherat ${ }^{5}$, Yoan Mboussou' ${ }^{1}$, Florence Naze', Sandrine Picot ${ }^{1}$, Malik Boukerrou ${ }^{4,6}$, Pierre-Yves Robillard ${ }^{4,6}$ and Patrick Gérardin ${ }^{5,7^{*}}$

\begin{abstract}
Background: Q fever (Coxiella burnetii infection) has been associated with adverse perinatal outcomes. After investigating the obstetrical importance of $\mathrm{Q}$ fever on Reunion island and demonstrating an association between incident $\mathrm{Q}$ fever and miscarriage, we conducted a cross-sectional serosurvey to assess the prevalence of Coxiella burnetii infection among parturient women.

Methods: Between January 9 and July 24, 2014, within the level-4 maternity of Saint Pierre hospital and the level-1 maternity of Le Tampon, we proposed to screen all parturient women for Coxiella burnetii serology. Seropositivity was defined using indirect immunofluorescence for a dilution of phase $2 \mathrm{lgG}$ titre $\geq 1: 64$. Further dilutions were chosen to discriminate recent or active infections from past or prevalent infections $(<1: 128)$ and classify these as either possible (1:128), or probable ( $\geq 1: 256)$. Recurrent miscarriage, stillbirth, preterm birth, small-for-gestational as well as a composite outcome of these adverse pregnancy outcomes were compared according to seropositivity using bivariate analysis or propensity score matching of seropositive and seronegative women on confounding factors.

Results: Among 1112 parturient women screened for Q fever over this 7-month period, 203 (18.3\%) were seropositive. Overall weighted seroprevalence was of $20.1 \%(95 \% \mathrm{Cl}, 17.7-22.5 \%)$. Weighted seroprevalence of probable infections was $4.7 \%(95 \% \mathrm{Cl} 3.4-5.9 \%)$, while $>90 \%$ of positive serologies corresponded to past infections or false positives. Seropositivity was associated with none of the abovementioned adverse perinatal outcomes, whether in unpaired or matched analyses on propensity score.

(Continued on next page)
\end{abstract}

\footnotetext{
* Correspondence: patrick.gerardin@chu-reunion.fr

${ }^{5}$ INSERM CIC 1410 Epidémiologie Clinique, Centre Hospitalier Universitaire, Groupe Hospitalier Sud Réunion, CHU Réunion, BP 350, 97448 Saint Pierre, Cedex-Reunion, France

${ }^{7}$ UM 134 PIMIT Processus Infectieux en Milieu Insulaire Tropical, Université de La Réunion, INSERM 1187, CNRS 9192, IRD 249, CYROI, Sainte Clotilde, Reunion, France

Full list of author information is available at the end of the article
}

(c) The Author(s). 2020 Open Access This article is licensed under a Creative Commons Attribution 4.0 International License, which permits use, sharing, adaptation, distribution and reproduction in any medium or format, as long as you give appropriate credit to the original author(s) and the source, provide a link to the Creative Commons licence, and indicate if changes were made. The images or other third party material in this article are included in the article's Creative Commons licence, unless indicated otherwise in a credit line to the material. If material is not included in the article's Creative Commons licence and your intended use is not permitted by statutory regulation or exceeds the permitted use, you will need to obtain permission directly from the copyright holder. To view a copy of this licence, visit http://creativecommons.org/licenses/by/4.0/. The Creative Commons Public Domain Dedication waiver (http://creativecommons.org/publicdomain/zero/1.0/) applies to the data made available in this article, unless otherwise stated in a credit line to the data. 
(Continued from previous page)

Conclusion: The magnitude and the pattern of seroprevalence suggest that $\mathrm{Q}$ fever is endemic on Reunion island. In this context, we found no significant contribution of prevalent Coxiella burnetii infection to adverse pregnancy outcomes. Although reassuring, these data put in our endemic context, with a previously demonstrated increased risk of incident $\mathrm{Q}$ fever associated miscarriage, encourage us to protect pregnant women against the risk of new infection, periconceptional or early in pregnancy.

Keywords: Immunofluorescence, Cross sectional study, Q fever, Coxiella burnetii, Pregnancy, Childbirth, Parturient woman, Prevalence, Prevalence proportion ratio, Propensity score matching

\section{Background}

Coxiella burnetii infection, best known as $\mathrm{Q}$ fever in humans, is a zoonotic disease, which has been reported from almost every country worldwide [1]. Coxiella burnetii is an obligate Gram negative intracellular bacterium that resides in wild and domesticated animals. Cattle, goats and sheep serve as reservoir to spread the bacterium to human populations $[1,2]$. This pathogen exhibits a strong tropism for the reproductive apparatus, which is the cause of complications, including spontaneous abortion (miscarriage), preterm delivery and foetal deaths [2]. Humans may be infected directly through handling of birth products or contact with bodily fluids, but most of the disease burden is believed to come from infected aerosols of farm animals [1].

In the sero-epidemiologic studies of pregnant woman, Q fever has been associated inconsistently with miscarriage [3-5], preterm birth [6-8], or low birthweight [8], and infrequently with foetal death [9], or congenital malformations [9], whilst smallfor-gestational age (intrauterine growth restriction) and oligohydramnios are classical complications only reported from case series [10-12]. These adverse pregnancy outcomes (APOs) have been associated with both acute and persistent $\mathrm{Q}$ fever infections [1]. They are likely the consequence of a placental immune dysregulation with an interleukin-10 overproduction, subsequent silencing of the dendritic cells, which favours bacterial replication within the trophoblast cell vacuoles of the allantochorion that express lysosomal markers [1]. Notwithstanding, causal relationship between a positive Coxiella burnetii serology and APOs remains elusive given discrepancies between case series and observational studies.

Following the documentation of $\mathrm{Q}$ fever endocarditis on Reunion island [13], demonstration of a significant contribution of acute infections to miscarriage and, to lesser extent, stillbirth [14], we conducted a crosssectional serosurvey to assess the prevalence of Coxiella burnetii antibodies among parturient women. Our secondary objectives were to search for risk factors and evaluate the contribution of seropositivity to APOs.

\section{Methods}

\section{Setting and population}

The characteristics of the study place have been described previously [14] and can be found at https:// bmcinfectdis.biomedcentral.com/articles/10.1186/s12 879-019-4619-6.

Between January 9 and July 24, 2014, all parturient women attending the regional perinatal healthcare centre of Saint Pierre hospital (level-4 maternity) and the private maternity of Le Tampon (level-1 maternity) were asked to be screened for Coxiella burnetii serology in addition to the usual data collection of a birth registry $[15,16]$.

\section{Serology}

Sera were tested using an indirect fluorescent antibody (IFA) assay with commercially available antigens for Coxiella burnetii (Coxiella burnetti I + II IFA IgG/IgM/ IgAt ${ }^{\circ}$, Vircell, Grenade, Spain). Seropositivity was defined for a phase 2 or phase 1 IgG titre $\geq 1: 64$ with or without phase $2 / 1 \operatorname{Ig} M \geq 1: 48$. Further dilutions were chosen to discriminate recent or active infections from past or prevalent infections (IgG2 $<1: 128$ and $\operatorname{IgM} 2<1$ : 48) and classify these as either possible (IgG2 $=1: 128$ and/or IgM2 $\geq 1: 48$ ), or probable (IgG2 $\geq 1: 256$ whatever IgM level). The use of phase 2 IgM alone were deemed only suggestive of recent infection and did not enter in the case definitions, as recommended by Netherlands experts [17]. These thresholds were chosen conservative to fulfil the National Reference Centre requirements and minimize the false positives [18]. Persistent infection was defined for a phase 1 to phase 2 IgG ratio $>1$ in the absence of IgM antibodies [19].

\section{Statistical analysis}

Statistical analyses were performed using Stata $14.2^{\circ}$ (StataCorp, College Station; Texas, USA). Crude seroprevalence rates were estimated with $95 \%$ confidence intervals $(\mathrm{CI})$, next they were weighted on the maternity of childbirth, marital status, country of birth, education, occupation and a homemade social deprivation index [20] to account for the structure of the reproductive population. 
Associations between maternal variables (maternity of childbirth, residence area, neighbourhood deprivation, age, origin, marital status, education, occupation and parity) and seropositive status were determined using crude and weighted chi-square tests, unadjusted and population-readjusted log-binomial models to identify potential risk factors. In these, prevalence proportion ratios (PPR) and 95\%CI were estimated as association measures.

Recurrent miscarriage (foetal demise $<22$ weeks or $\leq$ 500 g.), stillbirth (foetal death $\geq 22$ weeks or $>500$ g.), preterm birth $(<37$ weeks), small-for-gestational age (birthweight $<10$ th percentile), congenital malformations (ICD-10 codes), oligohydramnios or polyhydramnios, as well as a composite outcome of these APOs were compared according to Coxiella burnetii antibodies using bivariate analysis or propensity score matching of seropositive and seronegative women on putative confounders with complete data, namely maternal hypertension, diabetes, addiction and foetal gender. All these estimations were re-adjusted using sampling fractions to account for selection bias. A $P$ value $<0.05$ was considered significant.

\section{Results}

Over a 7-month period, 3123 pregnant women delivered in the southern Reunion island maternities. Among these, 1112 parturient women were screened for $\mathrm{Q}$ fever (Fig. 1). The participation was higher in the level-1 maternity than in the level-3 maternity ( $80 \%$ versus $25 \%$ ). The sample studied differed from the reproductive population for several maternal characteristics including the maternity of childbirth, neighbourhood deprivation, marital status, education, and occupation (Table S1), which imposed to weight the analysis on these variables to control the selection bias.

Seropositivity rate of Q fever was of 18.3\% (203/1112) and weighted seropositivity rate was of $20.1 \%$ (95\%CI, $17.7-22.5 \%$ ), among which a range of 93.4 to $96.1 \%$ corresponded to past infections or false positives (Phase 2 $\operatorname{IgM}<1: 48)$. These figures were respectively of $12.3 \%$ $(137 / 1112)$ and $14.1 \%(95 \% \mathrm{CI}, 12.0-16.1 \%)$ with the more stringent cut-off $\geq 1: 128$ suggestive of possible infections, among which a range of 5.9 to $9.0 \%$ corresponded to recent or active infections (Phase $2 \operatorname{IgM} \geq 1$ : 48 ). At dilutions $\geq 1: 256$ indicative of probable infections, seroprevalence and weighted seroprevalence were of $4.0 \%(45 / 11112)$ and $4.7 \%(95 \% \mathrm{CI}, 3.4-5.9 \%)$, respectively, which gave potential to six recent or active infections of putative gestational onset (Phase $2 \operatorname{IgM} \geq 1: 48$ ). Of three women harbouring phase 1 IgG antibodies, one met the definition of a persistent infection with a titre of 1:128. The detail of the serologic responses to Coxiella burnetii antigens is displayed in Table 1.

None of the abovementioned eight maternal characteristics were associated with the seropositive status in bivariate analysis (Table 2). Single women, middle schooleducated women, nulliparous or multiparous women were more likely to be seropositive in populationreadjusted analysis (Table S2). Importantly, neither the maternal occupation nor the location of the residence area was associated with seropositivity in both types of analysis. Further dilutions failed to identify risk factors.

Seropositivity was not associated with any of the abovementioned APOs, whether in unpaired bivariate (Table 3), population-readjusted, or matched analyses

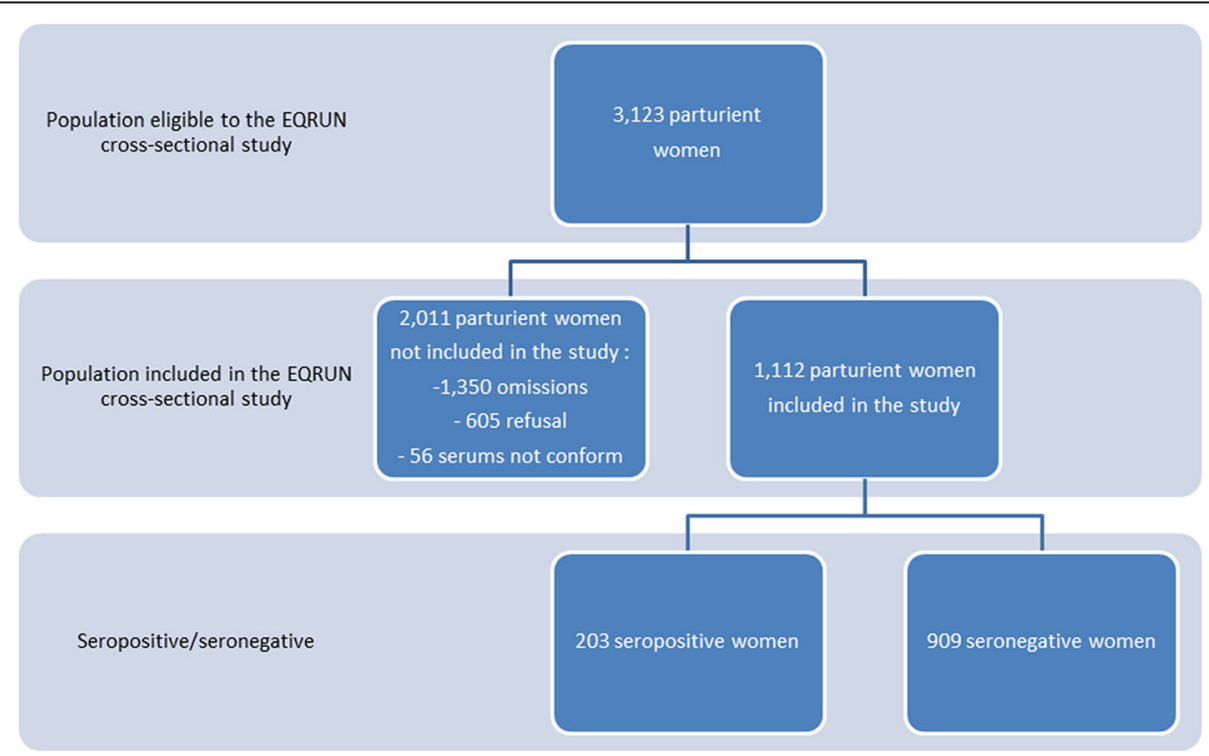

Fig. 1 Flow chart of the study population 
Table 1 Serologic responses to phase 2 lgM (recent infection), phase $1 \mathrm{lgG}$ (persistent infection) and phase $2 \mathrm{lgG}$ (recent/active infection) antigens among 1112 parturient women in southern Reunion island, January to July 2014

\begin{tabular}{lrrrrr}
\hline $\begin{array}{l}\text { Peripheral } \\
\text { blood titre }\end{array}$ & $\begin{array}{r}\text { Phase 2 } \\
\text { lgM } \\
\mathrm{n}(\%)\end{array}$ & $\begin{array}{r}\text { Phase 1 } \\
\mathrm{n}(\%)\end{array}$ & $\begin{array}{r}\text { Phase 2 } \\
\operatorname{lgG} \\
\mathrm{n}(\%)\end{array}$ & $\begin{array}{r}\text { Phase 2 lgM } \\
+\operatorname{lgG}, \mathrm{n}(\%)\end{array}$ & $\begin{array}{r}\text { Phase 2+1 } \\
\operatorname{lgG}, \mathrm{n}(\%)\end{array}$ \\
\hline $\mathbf{1 : 4 8}$ & $15(1.3)$ & - & - & $15(1.3)$ & - \\
$\mathbf{1 : 6 4}$ & - & $3(0.3)$ & $\begin{array}{r}203 \\
(18.3)\end{array}$ & $15(1.3)$ & $3(0.3)$ \\
$\mathbf{1 : 9 6}$ & $12(1.1)$ & - & - & $15(1.3)$ & - \\
$\mathbf{1 : 1 2 8}$ & - & $1(0.1)$ & 137 & $15(1.3)$ & $1(0.1)$ \\
$\mathbf{1 : 1 9 2}$ & $9(0.8)$ & - & - & $9(0.8)$ & - \\
$\mathbf{1 : 2 5 6}$ & - & $0(0.0)$ & $45(4.0)$ & $6(0.5)$ & $0(0.0)$ \\
$\mathbf{1 : 3 8 4}$ & $3(0.3)$ & - & - & $2(0.2)$ & - \\
$\mathbf{1 : 5 1 2}$ & - & $0(0.0)$ & $22(1.9)$ & & $0(0.0)$ \\
\hline
\end{tabular}

Data are decremental as the dilution progresses

(Table S3). Further adjustments on pregnancy related hypertensive disorders, diabetes, maternal addictions (smoking or alcohol), multiple pregnancy, or foetal gender, did not increase the risks of APOs with Q fever. Among the outcomes of the six women with recent or active infections of putative gestational onset, we noticed one small-for-gestational neonate, and one oligohydramnios. Of note, the outcome of phase 1 IgG was without harm to the foetus.

During the study period, 143 serologies were performed to diagnose $\mathrm{Q}$ fever outside the maternity, in various clinical indications. Among these, clinical and microbiological evaluation identified nine recent or active infections (phase $2 \operatorname{IgG} \geq 1: 256$ and phase 2 IgM: $\geq 1$ : 48) and six possible recent or active infections (phase 2 IgG 1:128 and phase 2 IgM: $\geq 1: 48$ ), which leads to a community-level annual incidence rate of 25.7 per 100 , 000 inhabitants.

\section{Discussion}

$Q$ fever is widely distributed in tropical areas and considered as endemic in Africa [1]. In the neighbouring Indian ocean, first isolations of Coxiella burnetii go back from the 1950's and sporadic infections have been reported both in autochthonous and traveller populations returning from Comoros, Madagascar or Reunion island [13]. In La Réunion, the overall seropositivity and shedding rates were of 11.8 and $0.8 \%$ in cattle, 1.4 and $4.4 \%$ in sheep and 13.4 and $20.1 \%$ in goats, respectively [2]. In humans, a population-based serosurvey conducted on stored frozen samples dated 2009 estimated the exposure around $6 \%[21]$.

Herein, we confirm the exposure of Reunion island pregnant women to autochthonous transmission of Coxiella burnetii. In agreement, we evidenced a threefold
Table 2 Maternal characteristics associated with Q fever seropositivity in bivariate analysis, among 1112 parturient women, Reunion island, January to July 2014

\begin{tabular}{|c|c|c|c|c|c|}
\hline \multicolumn{6}{|c|}{ Outcome: Coxiella burnetii Phase $2 \operatorname{lgG} \geq 1: 64$} \\
\hline Exposure variables & $n$ & Crude \% & Crude PPR & $95 \% \mathrm{Cl}$ & $P$ value \\
\hline Maternity centre & & & & & 0.146 \\
\hline Level-4, Saint Pierre & $127 / 645$ & 19.7 & 1.21 & $0.93-1.57$ & \\
\hline Level-1, Le Tampon & $76 / 467$ & 16.3 & 1 & & \\
\hline Area of residence & & & & & 0.563 \\
\hline North or East & $1 / 4$ & 25.0 & 1 & & \\
\hline West & $12 / 55$ & 21.8 & 0.87 & $0.14-5.12$ & \\
\hline South & $174 / 939$ & 18.5 & 0.74 & $0.13-4.07$ & \\
\hline \multicolumn{4}{|c|}{ Neighbourhood deprivation ${ }^{a}$} & & 0.838 \\
\hline Minimum & $91 / 477$ & 19.1 & 1 & & \\
\hline Intermediate & $66 / 346$ & 19.1 & 1.00 & $0.75-1.33$ & \\
\hline High & $30 / 175$ & 17.1 & 0.89 & $0.61-1.31$ & \\
\hline Age & & & & & 0.172 \\
\hline$\leq 25$ years & $81 / 424$ & 19.1 & 1 & & \\
\hline $26-31$ years & $50 / 333$ & 15.0 & 0.79 & $0.57-1.08$ & \\
\hline $32-47$ years & $72 / 355$ & 20.3 & 1.06 & $0.80-1.41$ & \\
\hline Place of birth & & & & & 0.302 \\
\hline Reunion & $141 / 771$ & 18.3 & 1.08 & $0.74-1.57$ & \\
\hline Indian ocean & $17 / 67$ & 25.4 & 1.50 & $0.88-2.57$ & \\
\hline Metropolitan France & $27 / 160$ & 16.9 & 1 & & \\
\hline Marital Status & & & & & 0.076 \\
\hline In couple & $125 / 723$ & 17.3 & 1 & & \\
\hline Celibacy & $60 / 270$ & 22.2 & 1.29 & $0.97-1.69$ & \\
\hline Education & & & & & 0.349 \\
\hline Primary school & $9 / 44$ & 20.5 & 1.24 & $0.65-2.33$ & \\
\hline Middle school & $38 / 165$ & 23.0 & 1.39 & $0.96-2.02$ & \\
\hline High school & $77 / 383$ & 20.1 & 1.21 & $0.88-1.67$ & \\
\hline University & $54 / 327$ & 16.5 & 1 & & \\
\hline Occupation & & & & & 0.421 \\
\hline Unemployed & $120 / 601$ & 20.0 & 1.19 & $0.90-1.56$ & \\
\hline Farmer & $0 / 2$ & 0.0 & NA & & \\
\hline Other work & $67 / 400$ & 16.7 & 1 & & \\
\hline Parity & & & & & 0.236 \\
\hline Nullipara & 77 / 407 & 18.9 & 1.17 & $0.85-1.60$ & \\
\hline Primipara & $55 / 340$ & 16.2 & 1 & & \\
\hline Multipara & $57 / 264$ & 21.6 & 1.33 & $0.95-1.86$ & \\
\hline
\end{tabular}

Data are numbers, crude seropositive rates (\%), crude prevalence proportion ratios (PPR) and $95 \%$ confidence intervals $(95 \% \mathrm{Cl})$. NA: not assessed. $P$ values are given for Pearson chi2 tests and not for Wald tests

${ }^{a}$ Derived from a homemade social deprivation index categorising the 24 municipalities of the island into tree levels based on three indices: socioeconomic composition (three variables) [20]

higher seropositivity rate in parturient women than in the general population, but similar seroprevalences, around $4 \%$, with respect to probable infections. The discrepancy between the two populations in seropositivity rates could stem from a recruitment bias, our study having been conducted exclusively in the South Reunion 
Table 3 Adverse pregnancy outcomes associated with Q fever seropositivity in bivariate analysis, among 1112 parturient women, Reunion island, January to July 2014

\begin{tabular}{|c|c|c|c|c|c|}
\hline \multirow{2}{*}{$\begin{array}{l}\text { Adverse } \\
\text { pregnancy outcomes }\end{array}$} & \multicolumn{5}{|c|}{ Exposure variable: Coxiella burnetii Phase 2 lgG $\geq 1: 64$} \\
\hline & $\mathrm{n}$ & Crude $\%$ & Crude PPR & $95 \% \mathrm{Cl}$ & $P$ value \\
\hline Composite outcome ${ }^{a}$ & & & & & 0.567 \\
\hline In seropositive & $52 / 203$ & 25.6 & 0.93 & $0.71-1.20$ & \\
\hline In seronegative & $251 / 909$ & 27.5 & 1 & & \\
\hline Preterm birth & & & & & 0.775 \\
\hline In seropositive & $11 / 203$ & 5.4 & 0.91 & $0.48-1.71$ & \\
\hline In seronegative & $54 / 909$ & 5.9 & 1 & & \\
\hline Small-for-gestational age & & & & & 0.823 \\
\hline In seropositive & $41 / 203$ & 20.2 & 0.97 & $0.71-1.31$ & \\
\hline \multirow[t]{2}{*}{ In seronegative } & $190 / 909$ & 20.9 & 1 & & \\
\hline & \multicolumn{5}{|c|}{ Exposure variable: Coxiella burnetii Phase $2 \lg G \geq 1: 256$ or Phase $2 \lg M \geq 1: 48$} \\
\hline Composite outcome ${ }^{a}$ & & & & & 0.801 \\
\hline In seropositive & $13 / 45$ & 28.9 & 1.06 & $0.66-1.70$ & \\
\hline In seronegative & $290 / 1067$ & 27.2 & 1 & & \\
\hline Preterm birth & & & & & 0.319 \\
\hline In seropositive & $1 / 45$ & 2.2 & 0.37 & $0.05-2.61$ & \\
\hline In seronegative & $64 / 1067$ & 6.0 & 1 & & \\
\hline Small-for-gestational age & & & & & 0.897 \\
\hline In seropositive & $9 / 45$ & 20.0 & 0.96 & $0.53-1.74$ & \\
\hline In seronegative & 222 / 1067 & 20.8 & 1 & & \\
\hline
\end{tabular}

Data are numbers, crude seropositive rates (\%), crude prevalence proportion ratios (PPR) and 95\% confidence intervals (95\% Cl). NA: not assessed. $P$ values are given for Wald tests and not for crude Pearson chi2 tests

${ }^{a}$ Recurrent miscarriage, stillbirth, or preterm birth, small-for-gestational age, congenital malformations, oligohydramnios or polyhydramnios

island maternities that welcome the Southern and Western pregnant populations, the more exposed to smallruminant farms and tradewinds [2]. Cross reactions are unlikely, given their proportion was slight (4\%) in the general population [21]. The congruence in the seroprevalence of acute infections may advocate equality of the two populations against the risk of an unrecognized airborne threat.

Compared to other seroepidemiologic studies found in the literature, the seropositivity rate found in Reunionese pregnant women was 2 to 5 -fold higher than those observed in endemic western countries $[6,8,22]$ and on average, far higher than those retrieved from Caribbean islands [23], while the seroprevalence of acute infections was 20 to 30 -fold higher than those observed in endemic [7, 8, 24] or hyperendemic settings (Table S4) [25]. Together with a high magnitude incidence, these seroepidemioologic data may account for an endemic setting, or even an unrecognized hyperendemic setting.

Given institutional constraints, we were unable to deploy the initial investigation that had been planned to include both individual and contextual risk factors, so that we did have access only to routine birth registry data. Thereby, we failed to identify risk factors from our serosurvey. Importantly, it was shown both in the Netherlands and Denmark that pregnant women living in the vicinity of livestock animals [24], especially in the vicinity of goat farms [22], exhibit higher phase 2 antibody titres and were more likely to develop an acute infection than women not exposed to small ruminants.

Of note, seropositivity was not associated with adverse pregnancy outcomes (i.e, that means that seropositivity was more likely reminiscent of past infection than of recent or active infection during the pregnancy), whether in unpaired or matched analysis, which strongly contrasts with incident (i.e., active) infections that were responsible of miscarriages, and to a lesser extent, of stillbirths in a preliminary prospective cohort study [14]. This is consistent with previous knowledge on $\mathrm{Q}$ fever that is well known to be abortive [1, 2, 4] and to cause intrauterine foetal death [9]. This is also coherent with data acquired from TORCH pathogens [26] or congenital flavivirus infections $[27,28]$, e.g., zika virus or dengue virus, for which the active or symptomatic character of the infection increases the risk of vertical transmission and adverse pregnancy outcomes. Importantly, none of the women harbouring phase 1 IgG was symptomatic or delivered an infant with an adverse foetal outcome, 
which does no plaid for the use of a low phase $1 \operatorname{IgG}$ cut-off or the phase 1 to phase 2 IgG ratio alone to define persistent infection.

\section{Limitations}

\section{Limitations of the study}

This study has potential limitations. First, it may be prone to residual selection bias given participation rate was much lower than anticipated, and the study sample was skewed towards women living in better socioeconomic conditions (more advantageous neighbourhoods, birthplace in mainland France, living in couple, higher level of education). This may persist even despite reweighting our sample to compensate this limitation. Second, we cannot exclude a misclassification bias owed to serology cross reactions between Coxiella burnetii and Rickettsia species, given the high proportion (33\%) of cross-reactive sera observed in the community [21]. However, given people with cross-reactive serum were at $70 \%$ located in the western dryer part of the island area also exposed to murine typhus [29], we believe that the pregnant women sampled in our study, mostly based in South Reunion, were less likely prone to multiple infections than women dwelling in the West, so this was unlikely to change the overall magnitude of the reproductive population exposure to Coxiella burnetii. These things being said, we concede the need of more specific methods for interpreting serosurvey data, such as Western Blot or seroneutralization, allowing the identification at the species level.

\section{Conclusions}

The magnitude and the pattern of seroprevalence in pregnant women suggest that $\mathrm{Q}$ fever is endemic on Reunion island. In this context, we found no significant contribution of prevalent Coxiella burnetii infections in adverse pregnancy outcomes. These results are reassuring for the population of childbearing age and contrast with those of incident Coxiella burnetii infection that are associated with an increased risk of miscarriage, or even with an increased risk of stillbirth. In accordance, we advocate as mitigation measure aimed at limiting the burden of $\mathrm{Q}$ fever on reproduction that pregnant women should be kept away from farms to rule out airborne transmission, avoid direct contact with ruminants or their byproducts, or to consume uncooked farm products.

\section{Supplementary information}

Supplementary information accompanies this paper at https://doi.org/10. 1186/s12879-020-04969-w.

Additional file 1: Table S1. Data are case numbers ( $\mathrm{N}$ and $\mathrm{n}$ ) and percentages. \#Derived from a homemade social deprivation index categorising the 24 municipalities of the island into tree levels based on three indices: socio-economic composition (three variables) [20]. Table S2. Data are numbers, weighted seropositive rates (\%), populationreadjusted prevalence proportion ratios (PPR) and $95 \%$ confidence intervals $(95 \% \mathrm{Cl})$. NA: not assessed. P values are given for weighted chi2 tests and not for Wald tests. \#Derived from a homemade social deprivation index categorising the 24 municipalities of the island into tree levels based on three indices: socio-economic composition (three variables) [20]. Table S3. Data are numbers that are not cumulative, crude seropositive rates (\%), population-readjusted prevalence proportion ratios (PPR), matched odd ratios (OR), and 95\% confidence intervals (95\% CI). NA: not assessed. P values are given for Wald tests and not for Pearson chi2 tests. *Recurrent miscarriage, stillbirth, or preterm birth, small-for-gestational age, congenital malformations, oligohydramnios or polyhydramnios. Seropositive women were matched with as many seronegative women as possible on maternal hypertension, diabetes, addiction and foetal gender. Table S4. Data are percentages.

\section{Abbreviations}

APOs: Adverse pregnancy outcomes; CPP: Comité de Protection des Personnes; IFA: Indirect fluorescent antibody (alternatively taken as immunofluorescent assay); IgA: Immunoglobulin A; IgG: Immunoglobulin G; IgG2: Phase 2 immunoglobulin G; IgM: Immunoglobulin M; 95\%Cl: 95\% confidence interval; PPR: Prevalence proportion ratio; TORCH: Toxoplasmosis, Other (syphilis, varicella-zoster, parvovirus B19), Rubella, Cytomegalovirus, Herpes)

\section{Acknowledgements}

The contributors acknowledge all the staff of the maternities and the members of the CIC-EC de la Réunion, our beloved and regretted friend, Doctor Alain Michault, for funding and benevolent supervision of this study, as well as Dr. Eric Cardinale at the CIRAD for helpful discussions.

\section{Authors' contributions}

$\mathrm{JJ}, \mathrm{SL}$ and $\mathrm{PG}$ conceived and designed the experiments. LA, YM, FN, and $\mathrm{SP}_{1}$ performed the experiments including serology assays. $\mathrm{PG}$ and $\mathrm{SP}_{2}$ designed the sampling plan from the birth registry. PD, CSP, MB, PYR provided the data with courtesy from the birth registry. JJ, SL and PAG analysed the data. JJ wrote the initial draft and PG revised the manuscript, which was extensively reviewed and approved by all authors.

\section{Funding}

The E-Q-RUN program was supported by the APIDOM 2012 grant from the Groupement Interrégional de Recherche Clinique et d'Innovation Sud-Ouest Outre-Mer Hospitalier (GIRCI SOHO). The funder of the E-Q-RUN program did not participate in the design, preparation, data analysis, or decision to publish the manuscript. The authors are indebted to the GIRCI SOHO for funding the APIDOM grant.

\section{Availability of data and materials}

The dataset generated and/or analysed during the current study are not publicly available due to anonymity policy issues but are available from the corresponding author on request.

\section{Ethics approval and consent to participate}

The E-Q-RUN study was conducted in accordance with the Declaration of Helsinki and the French legislation for biomedical research (Nu ID RCBAFSSAPS: 2013-A00397-38/ NCT02898402). It was approved both by the Comité de Protection des Personnes (CPP) of Bordeaux 2 University (2013/36), the Comité Consultatif sur le Traitement de I'Information en matière de Recherche dans le domaine de la Santé (CCTIRS) of Paris (2013/13.275 bis). These allowed the use of clinical and serum data after oral consent was obtained from all parturient women aged $\geq 18$ years, as proposed for standard care in French university hospitals (Article L1121 du Code de la Santé Publique, modifié par ordonnance n²010-177 du 23/02/2010). Written consent was not warranted given the procedure of blood sampling was included in those required for per partum monitoring under standard care.

The oral consent was informed by the means of an information sheet which was explained face to face by the investigators. The data collection (2013/ 
913371) was curated under the rules of the Comission Nationale de I'Informatique et des Libertés (CNIL).

\section{Consent for publication}

Not applicable.

\section{Competing interests}

The authors declare that they have no competing interests.

\section{Author details}

'Laboratoire de Bactériologie, Virologie et Parasitologie, Centre Hospitalier Universitaire (CHU) de la Réunion, Saint Pierre, Reunion, France. ${ }^{2} \mathrm{CIRE}$ Océan Indien, Santé Publique France, French National Public Health Agency, Saint Denis, Reunion, France. ${ }^{3}$ Maternité, Clinique Durieux, Le Tampon, Reunion, France. ${ }^{4}$ Maternité, Pôle Femme Mère Enfant, CHU de la Réunion, St Pierre, Reunion, France. ${ }^{5}$ INSERM CIC 1410 Epidémiologie Clinique, Centre Hospitalier Universitaire, Groupe Hospitalier Sud Réunion, CHU Réunion, BP 350, 97448 Saint Pierre, Cedex-Reunion, France. ${ }^{6}$ CEPOI-EA7388, Pôle Femme Mère Enfant, CHU de la Réunion, Saint Pierre, Reunion, France. ' UM 134 PIMIT Processus Infectieux en Milieu Insulaire Tropical, Université de La Réunion, INSERM 1187, CNRS 9192, IRD 249, CYROI, Sainte Clotilde, Reunion, France.

Received: 18 March 2019 Accepted: 12 March 2020

Published online: 03 April 2020

\section{References}

1. Eldin C, Melenotte C, Mediannikov O, Ghigo E, Million M, Edouard S, et al. From Q fever to Coxiella burnetii infection: a paradigm change. Clin Microbiol Rev. 2017;30:115-90.

2. Cardinale E, Esnault O, Beral M, Naze F, Michault A. Emergence of Coxiella burnetti in ruminants on Reunion island? Prevalence and risk factors. PLoS Negl Trop Dis. 2014:8:e3055.

3. Baud D, Peter O, Langel C, Regan L, Greub G. Seroprevalence of Coxiella burnetii and Brucella abortus among pregnant women. Clin Microbiol Infect. 2009;15:499-501.

4. Quijada SG, Terán BM, Murias PS, Anitua AA, Cermeño JL, Frías AB. Q fever and spontaneous abortion. Clin Microbiol Infect. 2012;18:533-8.

5. Nielsen SY, Hjøllund NH, Andersen AM, Henriksen TB, Kantsø B, Krogfelt KA, et al. Presence of antibodies against Coxiella burnetii and risk of spontaneous abortion: a nested case-control study. PLoS One. 2012;7: e31909.

6. van der Hoek W, Meekelenkamp JC, Leenders AC, Wijers N, Notermans DW, Hukkelhowen CW. Antibodies against Coxiella burnetii and pregnancy outcomes during the 2007-2008 Q fever outbreaks in the Netherlands. BMC Infect Dis. 2011;11:44.

7. Nielsen SY, Andersen AM, Mølbak K, Hjøllund NH, Kantsø B, Krogfelt KA, et al. No excess risk of adverse pregnancy outcomes among women with serological markers of previous infection with Coxiella burnetii: evidence from the Danish National Birth Cohort. BMC Infect Dis. 2013;13:87.

8. Langley JM, Marrie TJ, Leblanc JC, Almudevar A, Resch L, Raoult D. Coxiella burnetii seropositivity in parturient women is associated with adverse pregnancy outcomes. Am J Obst Gynecol. 2003;189:228-32.

9. Million M, Roblet F, Carles D, D'Amato F, Protopopescu C, Carrieri MP, et al. Reevaluation of the risk of fetal death and malformation after Q fever. Clin Infect Dis. 2014:59:256-60.

10. Carcopino X, Raoult D, Bretelle F, Boubli L, Stein A. Managing Q fever during pregnancy: the benefits of long-term cotrimoxazole therapy. Clin Infect Dis. 2007;45:548-55.

11. Nielsen SY, Mølbak K, Henriksen TB, Krogfelt KA, Larsen CS, Villumsen S. Adverse pregnancy outcomes and Coxiella burnetii antibodies in pregnant women, Denmark. Emerg Infect Dis. 2014;20:925-31.

12. Coste Mazeau P, Hantz S, Eyraud JL, Donadel L, Lacorre A, Rogez S, et al. Q fever and pregnancy: experience from the Limoges Regional University Hospital. Arch Gynecol Obstet. 2016;294:233-8.

13. Marie-Blandine Gottis. Épidémiologie des infections chroniques à Coxiella Burnetii sur l'île de la Réunion, une étude rétrospective de 2007 à 2015. Médecine humaine et pathologie. 2016. <dumas01290818>. https://dumas. ccsd.cnrs.fr/dumas-01290818/document.
14. Mboussou Y, Jaubert J, Larrieu S, Atiana L, Naze F, Folio C, et al. Pregnancy outcomes of Q fever: prospective follow-up study on Reunion island. BMC Infect Dis. 2019;19:1001.

15. Roman H, Robillard PY, Verspyck E, Hulsey TC, Marpeau L, Barau G. Obstetric and neonatal outcomes in grand multiparity. Obstet Gynecol. 2004:103:124-9.

16. Robillard PY, Dekker G, Boukerrou M, Le Moullec N, Hulsey TC. Relationship between pre-pregnancy maternal BMI and optimal weight gain in singleton pregnancies. Helyon. 2018;4:e00615.

17. Hanssen DAT, Morroy G, de Lange MMA, Wielders CCH, van der Hoek W, Dijkstra F, et al. Notification data and criteria during a large Q-fever epidemic reassessed. Epidemiol Infect. 2019;147:e191.

18. Parker NR, Barralet JH, Bell AM. Q fever. Lancet. 2006;367:679-88.

19. Dupont HT, Thirion X, Raoult D. Q fever serology cut-off determination for microimmunofluorescence. Clin Diagn Lab Immunol. 1994;1:189-96.

20. Fred A, Fianu A, Béral M, Guernier V, Sissoko D, Méchain M, et al. Individual and contextual risk factors for chikungunya virus infection: the SEROCHIK cross-sectional population-based study. Epidemiol Infect. 2018;146:1056-64.

21. Jaubert J, Naze F, Camuset G, Larrieu S, Pascalis H, Guernier V, et al. Seroprevalence of Coxiella burnetii ( $Q$ fever) exposure in humans on Reunion Island. Open Forum Infect Dis. 2019;6:ofz227.

22. van der Hoek W, Meekelenkamp JC, Dijkstra F, Notermans DW, Bom B, Vellema $\mathrm{P}$, et al. Proximity to goat farms and Coxiella burnetii seroprevalence among pregnant women. Emerg Infect Dis. 2011:17:2360-3.

23. Wood H, Drebot MA, Dewailly E, Dillon L, Dimitrova K, Forde M, et al. Seroprevalence of seven zoonotic pathogens in pregnant women from the Caribbean. Am J Trop Med Hyg. 2014;91:642-4.

24. Nielsen SY, Molbak K, Nybo Andersen AM, Brink Henriksen T, Kantso B, Krogfelt KA, et al. Prevalence of Coxiella burnetii in women exposed to livestock animals, Denmark, 1996 to 2002. Euro Surveill. 2013;18(28).pii: 20528.

25. Rey D, Obadia Y, Tissot-Dupont H, Raoult D. Seroprevalence of antibodies to Coxiella burnetii among pregnant women in south eastern France. Eur J Obstet Gynecol Reprod Biol. 2000;93:151-6.

26. Adams-Waldorf KM, Mc Adams RM. Influence of infection during pregnancy on fetal development. Reproduction. 2013;146:R151-62.

27. Paixão ES, Costa MDCN, Teixeira MG, Harron K, de Almeida MF, Barreto ML, et al. Symptomatic dengue infection during pregnancy and the risk of stillbirth in Brazil, 2006-12: a matched case-control study. Lancet Infect Dis. 2017:17:957-64

28. Pomar L, Vouga M, Lambert V, Pomar C, Hcini N, Jolivet A, et al. Maternalfetal transmission and adverse perinatal outcomes in pregnant women infected with Zika virus: prospective cohort study in French Guiana. BMJ. 2018:363:k443.

29. Gérardin P, Zemali N, Bactora M, Camuset G, Balleydier E, Pascalis H, et al. Seroprevalence of typhus group and spotted fever group Rickettsia exposures on Reunion island. BMC Res Notes. 2019;12:387.

\section{Publisher's Note}

Springer Nature remains neutral with regard to jurisdictional claims in published maps and institutional affiliations.

Ready to submit your research? Choose BMC and benefit from:

- fast, convenient online submission

- thorough peer review by experienced researchers in your field

- rapid publication on acceptance

- support for research data, including large and complex data types

- gold Open Access which fosters wider collaboration and increased citations

- maximum visibility for your research: over $100 \mathrm{M}$ website views per year

At $\mathrm{BMC}$, research is always in progress.

Learn more biomedcentral.com/submissions 